\title{
Morphological Development of Embryo, Larvae and Juvenile in Yellowtail Kingfish, Seriola lalandi
}

\author{
Sang Geun Yang ${ }^{1}$, Sang Woo Hur ${ }^{2}$, Seung Cheol $\mathrm{Ji}^{1}$, Sang Gu Lim ${ }^{1}$, Bong Seok Kim ${ }^{1}$, \\ Minhwan Jeong ${ }^{1}$, Chi Hoon Lee ${ }^{2}$ and ${ }^{\dagger}$ Young-Don Lee ${ }^{2}$ \\ ${ }^{1}$ Jeju Fisheries Research Institute, National Institute of Fisheries Science, Jeju 63610, Korea \\ ${ }^{2}$ Marine Science Institute, Jeju National University, Jeju 63333, Korea
}

\begin{abstract}
This study monitored the morphological development of embryo, larvae and juvenile yellowtail kingfish, Seriola lalandi, for their aquaculture. The fertilized eggs obtained by natural spawning were spherical shape and buoyant. Fertilized eggs were transparent and had one oil globule in the yolk, with an egg diameter of $1.35 \pm 0.04 \mathrm{~mm}$ and an oil globule diameter of $0.32 \pm 0.02 \mathrm{~mm}$. The fertilized eggs hatched $67-75 \mathrm{~h}$ after fertilization in water at $20 \pm 0.5^{\circ} \mathrm{C}$. The total length (TL) of the hatched larvae was $3.62 \pm 0.16 \mathrm{~mm}$. During hatching, the larvae, with their mouth and anus not yet opened. The yolk was completely absorbed 3 days after hatching (DAH), while the TL of post-larvae was $4.72 \pm 0.07 \mathrm{~mm}$. At $40 \mathrm{DAH}$, the juveniles had grown to $30.44 \pm 4.07 \mathrm{~mm}$ in TL, body depth increased, the body color changed to a black, yellow, and light gray-blue color, and 3-4 vertical stripes appeared. At $45 \mathrm{DAH}$, the juveniles were $38.67 \pm 5.65 \mathrm{~mm}$ in TL and $10.10 \pm 0.94$ $\mathrm{mm}$ in body depth. The fish were green with a light orange color, with 7 faint green-brown stripes on the sides of their body. At $87 \mathrm{DAH}$, the juveniles had grown to $236.11 \mathrm{~mm}$ in TL, $217.68 \mathrm{~mm}$ in fork length, and $136.5 \mathrm{~g}$ in weight. The fish resembled their adult form, with a light yellow-green body color, loss of the pattern on the sides of their body, and a yellow coloration at the tip of the caudal fin.
\end{abstract}

Key words : Yellowtail kingfish, Seriola lalandi, Fertilized egg, Larva, Juvenile

\section{INTRODUCTION}

There are 12 species of yellowtail (Seriola spp.) worldwide (family Carangidae, order Perciformes, subclass Actinopterygii) (Nakada, 2008). There are 3 known species of Seriola inhabiting the coasts of South Korea: yellowtail kingfish $(S$. lalandi), yellowtail (S. quinqueradiata), and greater amberjack (S. dumerili) (Kim et al., 2001). Yellowtail kingfish (S. lalandi) occur throughout the Atlantic, Pacific, and Indian Oceans, and in waters surrounding Japan and the United
States (Nakada, 2008). There are currently 4 known species of Seriola off the waters of Japan (Nakabo, 1993), of which yellowtail, yellowtail kingfish (S. lalandi), and greater amberjack are farmed. Between 1979 and 1998, approximately 150,000 tonnes of yellowtail were produced in Japan every year, despite seed production for yellowtail kingfish $(S$. lalandi) still being under development (Nakada, 2000; Nakada, 2002). Yellowtail farming in Australia and New Zealand began in early 2000; seed production there is currently in progress (Poortenaar et al., 2001). Yellowtail

\footnotetext{
Manuscript received May 05, 2016, Received in revised form May 08, 2016, Accepted May 15, 2016

${ }_{\dagger}^{\dagger}$ Corresponding Author: Young-Don Lee, Marine Science Institute, Jeju National University, Jeju 63333, Korea. Tel. : +82-64-782-8922, Fax : +82-64783-6066, E-mail: leemri@jejunu.ac.kr

This is an Open Access article distributed under the terms of the Creative Commons Attribution Non-Commercial License (http:// creativecommons.org/licenses/by-nc/3.0) which permits unrestricted non-commercial use, distribution, and reproduction in any medium, provided the original work is properly cited.
} 
kingfish (S. lalandi) are diadromous, and have great value worldwide as a fish for cultivation and for the leisure fishing industry. They are spring-summer spawning fish, and the greater amberjack shows oocytes from different stages of ovary development, suggesting that they spawn multiple times during a single spawning period (Nakada, 2008).

Research has been conducted on embryo development of S. lalandi inhabiting the coasts of Australia and New Zealand (Moran et al., 2007b), as well as those inhabiting the coasts of Japan (Fujita \& Yogata, 1984). There has also been research into the growth of juvenile $S$. lalandi (Fujita \& Yogata, 1984), and the morphological development of the digestive tract in juveniles (Chen et al., 2006a, b). However, the only research into developmental biology on yellowtail kingfish $(S$. lalandi) in South Korea has been a single study on induction of maturation and spawning characteristics.

This study aimed to explore developmental biological information for use in the rearing management of yellowtail kingfish (S. lalandi) for seed production. To this end, we describe the development process in fertilized eggs, as well as the growth, morphological development, and swimming characteristics of juvenile yellowtail kingfish (S. lalandi) according to age after hatching. We also aimed to devise methods for the management of seed rearing.

\section{MATERIALS AND METHODS}

\section{Acquisition of fertilized eggs}

The yellowtail kingfish ( $S$. lalandi) used in this study consisted of 59 individuals $(6.1-14.9 \mathrm{~kg})$, which had been caught from the wild off the coast of Jeju, South Korea. They were subsequently raised in a concrete indoor tank $\left(6.0 \mathrm{~m} \times 6.0 \mathrm{~m} \times 2.0 \mathrm{~m}\right.$, capacity $\left.100 \mathrm{~m}^{3}\right)$ at the Future Aquaculture Research Center, National Fisheries Research and Development Institute in South Korea. The fertilized eggs gathered were naturally spawned between early May 2014 , when the water temperature was $17.0^{\circ} \mathrm{C}$, and mid-
June, when the water temperature was $20.5^{\circ} \mathrm{C}$.

\section{Egg morphology and development}

In order to observe the morphology of yellowtail kingfish (S. lalandi) eggs, and the development processes in fertilized eggs, a pipette was used to collect $1 \mathrm{~mL}$ of fertilized eggs, which were retrieved immediately after natural spawning. These were moved to 2,000 $\mathrm{mL}$ beakers and managed in a still water system in a tank heated by an Aquarium Heater Green Bio (BS-5000, Dong Woo Electronic). The water was changed twice daily, with 50\% new filtered seawater. Aeration was not performed. The water temperature during embryo development was $20 \pm 0.5^{\circ} \mathrm{C}$. The time required for each stage of development after fertilization was defined as the time when at least $80 \%$ of the developmental stage was complete. Mean values were recorded from 3 repetitions. Observations were made using a stereoscopic dissection microscope (Nikon, SMZ745T).

\section{Management of water quality and supply of feed} for seed rearing

For the rearing of yellowtail kingfish (S. lalandi) seed, naturally spawned fertilized eggs were collected and reared in an indoor tank $\left(5.5 \mathrm{~m} \times 5.0 \mathrm{~m} \times 1.3 \mathrm{~m}\right.$, capacity $\left.27.5 \mathrm{~m}^{3}\right)$ at the Future Aquaculture Research Center, National Fisheries Research and Development Institute. Throughout the rearing period, the water temperature was maintained at $21.6 \pm 1.0^{\circ} \mathrm{C}$, while the salt content of the water was $32.1 \pm 0.7 \%$.

Food supply during the juvenile rearing period was as follows: from $2 \mathrm{DAH}$, the juveniles were supplied with rotifer (Brachionus plicatilis) that had been cultured in concentrated Chlorella extract (Daesang, Korea) and enriched for 8 hours with Bio DHA Marine Glos (Marineglos Co., Japan). From $8 \mathrm{DAH}$, the juveniles were provided with Artemia nauplius that had been enriched with SELCO (INVE, Belgium) for 8 hours. From 12 DAH, the juveniles 
were provided with an initial mixed particulate feed, with the size of the feed increasing sequentially. Finally, from $25 \mathrm{DAH}$, the juveniles were supplied with striped beakfish hatchlings (Oplegnathus fasciatus).

\section{Observing the morphological development of} juveniles

The morphological development of juveniles was observed and measured to a precision of $0.01 \mathrm{~mm}$ using a stereoscopic dissecting microscope (Nikon, Nikon, SMZ 745T) and a profile projector (PJ300, Mitutoyo). Immediately after hatching, 5 individuals were collected at random each day and anesthetized using low temperatures and MS-222 Sandoz (Tricaine methanesulfonate). Stages of juvenile morphological development were distinguished according to Russell (1976).

\section{RESULTS AND DISCUSSION}

Developmental biological information about the early life of fish, including the development of embryos and juveniles, is an important factor in understanding the life history of the species, and is a source of techniques for rearing management. In particular, there are many difficulties identifying the species of eggs and juveniles collected from the coast, and so information about morphology at different stages of embryo and juvenile development is essential (Byun, 2002; Song et al., 2013).

\section{Egg morphology}

The fertilized eggs of yellowtail kingfish ( $S$. lalandi) were spherical, with a diameter of $1.388 \pm 0.041 \mathrm{~mm}$. The eggs were buoyant, and possessed a single oil globule with a diameter of $0.378 \pm 0.029 \mathrm{~mm}$ (Table 1 and Fig. 1). A previous study into artificial insemination using hormone treatment in yellowtail kingfish $(S$. lalandi) reported an egg diameter and oil globule diameter of $1.36 \pm 0.07 \mathrm{~mm}$ and $0.34 \pm 0.02 \mathrm{~mm}$, respectively (Fujita \& Yogata, 1984). By comparison, the naturally spawned eggs in the present study were slightly larger, at $1.388 \pm 0.041 \mathrm{~mm}$ and 0.378 $\pm 0.029 \mathrm{~mm}$, respectively. The egg diameter and oil globule diameter for $S$. lalandi in California were reported as 1.36 $\pm 0.03 \mathrm{~mm}$ and $0.29 \pm 0.02 \mathrm{~mm}$ in 2009 , respectively, and as $1.40 \pm 0.05 \mathrm{~mm}$ and $0.31 \pm 0.05 \mathrm{~mm}$ in 2010 (Stuart \& Drawbridge, 2012). Measurements for S. lalandi in New Zealand were $1.40 \pm 0.04 \mathrm{~mm}$ and $0.31 \pm 0.01 \mathrm{~mm}$ (Moran et al, 2007a, b). In the present study, the egg diameter for $S$ lalandi in Korea can be considered similar to the California or the New Zealand yellowtail kingfish (S. lalandi), but the oil globule diameter tended to be slightly larger than those species.

\section{Embryonic development}

Fertilized eggs that had been induced by natural spawning (Fig. 1A) formed a blastodisc (1-cell stage) 40 min postfertilization (p.f.) (Fig. 1B). This blastodisc divided to form the 2-cell stage at $1 \mathrm{~h} 12 \mathrm{~min}$ p.f. (Fig. 1C). The 4cell stage was formed by cleavage at 1 h 46 min p.f. (Fig. 1D), and reached the 8-cell stage by 2 h 25 min p.f. (Fig. 1E). The 16-cell stage was achieved by 2 h 52 min p.f. (Fig. $1 \mathrm{~F}$ ), followed by the 32 -cell stage at $3 \mathrm{~h} 48 \mathrm{~min}$ p.f. (Fig. $1 \mathrm{G})$, and the 64-cell stage at $4 \mathrm{~h} 4 \mathrm{~min}$ (Fig. 1H). A morula was formed by 6 h 6 min p.f. (Fig. 1I), and a blastula was formed by 10 h 25 min p.f. (Fig. 1J). The early gastrula stage developed at 14 h 20 min p.f., while the blastoderm expanded towards the vegetal pole to cover the yolk (Fig. $1 \mathrm{~K})$. The blastoderm had covered most of the yolk by $21 \mathrm{~h}$ 21 min p.f. (Fig. 1L).

At $22 \mathrm{~h} 20 \mathrm{~min}$ p.f., the sphere closed and the outline of the embryo became clearly visible (Fig. 1M). At 24 h 2 min p.f., 10-11 myomeres were visible and Kupffer's vesicle formed (Fig. 1N). At 27 h 53 min p.f. 13 myomeres were visible and the auditory vesicles and eye lenses had also appeared (Fig. 1O). At 31 h 22 min p.f., the number of myomeres had increased to 18-19, the Kupffer's vesicle had disappeared, and melanophores became visible (Fig. 1P). At 34 h 6 min p.f., melanophores appeared on the 
SG Yang, SW Hur, SC Ji, SG Lim, BS Kim, M Jeong, CH Lee, Y-D Lee

Table 1. Development stage of natural spawning egg in yellowtail kingfish (S. lalandi) at $20 \pm 0.5^{\circ} \mathrm{C}$

\begin{tabular}{|c|c|c|c|}
\hline Developmental stage & Elapsed time & Remark & Features of eggs and embryos \\
\hline Fertilized egg & 0.0 & Fig. 1A & Spherical \& transparent with buoyancy \\
\hline 1 cell & $40 \mathrm{~min}$ & Fig. 1B & \\
\hline 2-cell & $1 \mathrm{~h} 12 \mathrm{~min}$ & Fig. 1C & First cleavage \\
\hline 4-cell & $1 \mathrm{~h} 46 \mathrm{~min}$ & Fig. 1D & Second cleavage, plane perpendicular to the first \\
\hline 8 -cell & $2 \mathrm{hrs} 25 \mathrm{~min}$ & Fig. 1E & Third cleavage, plane perpendicular to the second \\
\hline 16-cell & $2 \mathrm{hrs} 52 \mathrm{~min}$ & Fig. 1F & \\
\hline 32-cell & $3 \mathrm{hrs} 48 \mathrm{~min}$ & Fig. $1 \mathrm{G}$ & \\
\hline 64-cell & $4 \mathrm{hrs} 04 \mathrm{~min}$ & Fig. $1 \mathrm{H}$ & \\
\hline Morula & $6 \mathrm{hrs} 06 \mathrm{~min}$ & Fig. 1I & \\
\hline Blastula & $10 \mathrm{hrs} 25 \mathrm{~min}$ & Fig. 1J & Start of blastula stage \\
\hline Early gastrula & $14 \mathrm{hrs} 20 \mathrm{~min}$ & Fig. 1K & Blastoderm expanded towards the vegetal pole to cover the yolk \\
\hline Late gastrula & $21 \mathrm{hrs} 21 \mathrm{~min}$ & Fig. 1L & Blastoderm had covered most of the yolk \\
\hline Formation of embryo & $22 \mathrm{hrs} 20 \mathrm{~min}$ & Fig. $1 \mathrm{M}$ & Outline of the embryo became clearly visible \\
\hline Kupffer's vesicles & $24 \mathrm{hrs} 02 \mathrm{~min}$ & Fig. 1N & 10 to 11 myotomes were visible \\
\hline Auditory vesicles and eye lens & $27 \mathrm{hrs} 53 \mathrm{~min}$ & Fig. 10 & 13 myotomes were visible \\
\hline Melanophores appearance & $31 \mathrm{hrs} 22 \mathrm{~min}$ & Fig. 1P & 18 to 19 myotomes, melanophores appeared on the embryo \\
\hline Melanophores appearance & $34 \mathrm{hrs} 06 \mathrm{~min}$ & Fig. 1Q & Melanophores appeared on the yolk \\
\hline Heart beat & $54 \mathrm{hrs} 43 \mathrm{~min}$ & Fig. 1R & 28 to 30 myotomes, embryonic movements \\
\hline Hatching & $67 \mathrm{hrs}$ & Fig. 1S & Hatching begins \\
\hline
\end{tabular}

yolk (Fig. 1Q). At $54 \mathrm{~h} 43 \mathrm{~min}$ p.f., the number of myomeres had increased to $28-30$, while the brain had begun to differentiate (Fig. 1R). At $67 \mathrm{~h}$ p.f., the larvae first began to use their tails to break the egg membrane and hatch, with most larvae hatching by $67-75$ h p.f. (Fig. 1S).

The time from fertilization to hatching for yellowtail kingfish (S. lalandi) in $20 \pm 0.5^{\circ} \mathrm{C}$ water was $67-75 \mathrm{~h}$, which was faster than the $96 \mathrm{~h}$ measured in $15.5-20.4^{\circ} \mathrm{C}$ water in 1977 in Japan, and the $76 \mathrm{~h}$ measured in 20.0$21.4^{\circ} \mathrm{C}$ water in 1978 (Fujita \& Yogata, 1984). This is thought to be due to the effects of water temperature.

\section{Morphological development of larval and juvenile} yellowtail kingfish (S. lalandi)

The morphological development of yellowtail kingfish (S. lalandi) larvae and juveniles was observed in 3 stages: the pre-larvae stage, the post-larvae stage, and the juvenile stage (Table 2 and Fig. 2).

\section{1) Pre-larvae stage}

Newly hatched larvae had a TL of $3.62 \pm 0.16 \mathrm{~mm}$, with the longest diameter of the yolk being $1.54 \pm 0.06 \mathrm{~mm}$, and the oil globule diameter ranging from $0.33 \pm 0.01 \mathrm{~mm}$. The anus was a posterior to the center of the body, underneath myomere 12. The mouth had not yet open, and melanophores were deposited in the eyes. The yolk was oval-shaped and the oil globule was located at the anterior of the yolk. Melanophores were distributed in lines from the posterior part of the head towards the dorsal and ventral parts of each myomere. Xanthophores were distributed at the superior part of the head, along the midline dorsally and ventrally, and at the primordial fin of each larva. These xanthophores 

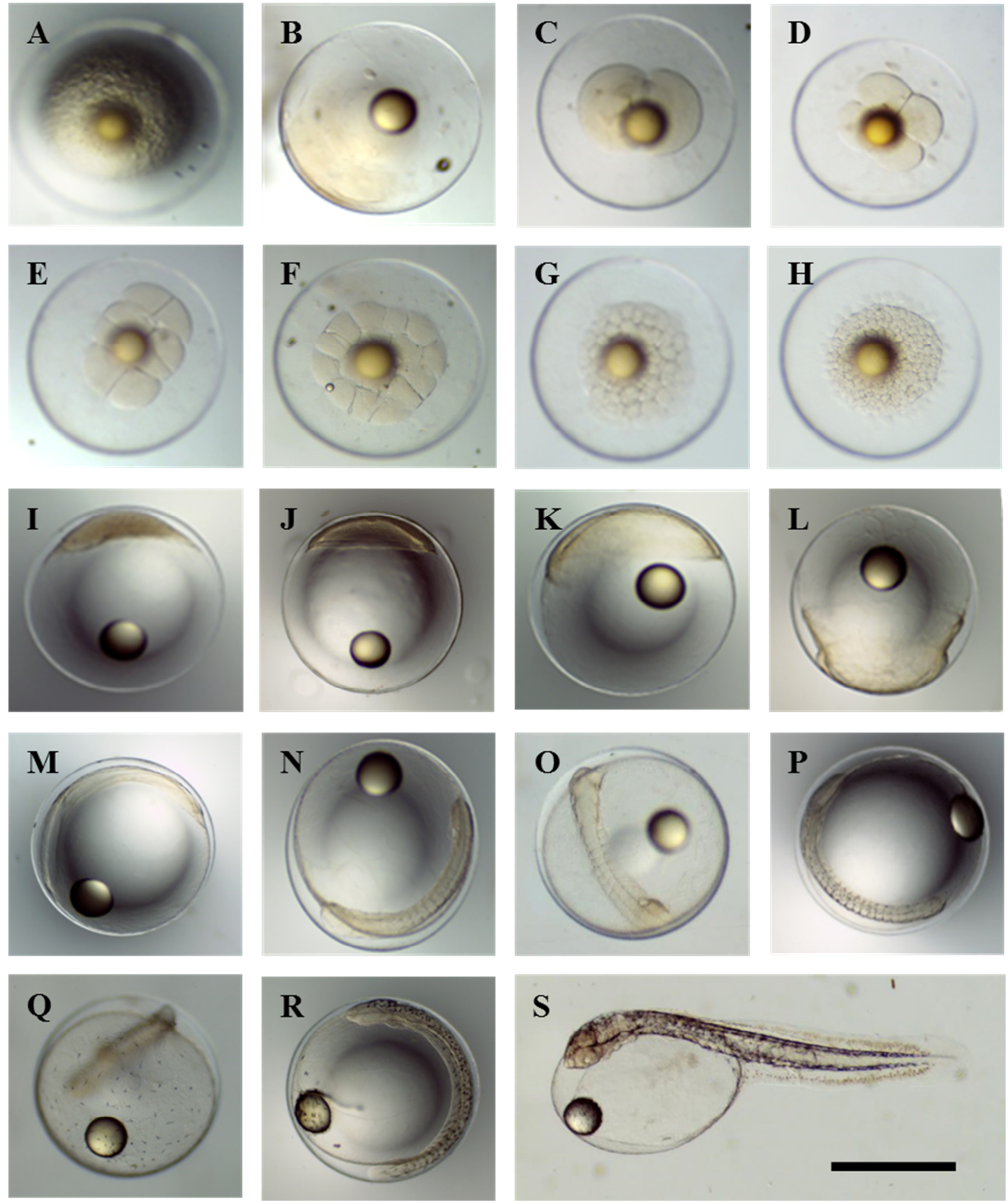

Fig. 1. Egg development and hatching of yellowtail kingfish (S. lalandi) at water temperature $20 \pm 0.5^{\circ} \mathrm{C}$. A, Fertilized egg; B, 1-cell stage (40 min); C, 2-cells stage (1 h $12 \mathrm{~min})$; D, 4-cells stage (1 h $46 \mathrm{~min})$; E, 8-cells stage (2 h. 25 min); F, 16-cells stage ( 2 h. 52 min); G 32-cells stage ( 3 h. 48 min); H, 64-cells stage (4 h. 04 min); I, morula stage (6 h. $06 \mathrm{~min})$; J, blastula stage (10 h. $25 \mathrm{~min})$; K, early gastrula stage (14 h. $20 \mathrm{~min})$; L, late gastrula stage ( $21 \mathrm{~h} .21 \mathrm{~min})$; M, formation of embryo (22 h. $20 \mathrm{~min}$ ); N, formation of Kupffer's vesicles, 10-11 myotomes stage (24 h. $02 \mathrm{~min}$ ), O: formation of auditory vesicles and eye lens (27 h. $53 \mathrm{~min})$; P, 18-20 myotomes stage, Kupffer's vesicles disappeared, melanophores appeared on the embryo (31 h. $22 \mathrm{~min})$; Q, melanophores appeared on the yolk (34 h. 06 min); R, heart beating, 28-30 myotomes stage (54 h. $43 \mathrm{~min}$ ); S, Hatching (67 h.).Scale bar indicates $1 \mathrm{~mm}$. 
Table 2. Development of larva and juveniles in yellowtail kingfish (S. lalandi) at $20 \pm 0.5^{\circ} \mathrm{C}$

\begin{tabular}{|c|c|c|c|}
\hline $\begin{array}{l}\text { Day after hatching } \\
\text { (DAH) }\end{array}$ & $\begin{array}{l}\text { Total length } \\
\quad(\mathrm{mm})\end{array}$ & Remark & Features of larva and juveniles \\
\hline $0 \mathrm{DAH}$ & $3.62 \pm 0.16$ & Fig. 2A & Pre-larvae stage \\
\hline $1 \mathrm{DAH}$ & $4.49 \pm 0.17$ & Fig. 2B & Primordial fin was extended broadly \\
\hline $2 \mathrm{DAH}$ & $4.69 \pm 0.16$ & Fig. $2 \mathrm{C}$ & Yolk was almost completely absorbed, mouth was open \\
\hline $3 \mathrm{DAH}$ & $4.72 \pm 0.07$ & Fig. 2D & $\begin{array}{l}\text { Xanthophores of the primordial fin appeared throughout almost the } \\
\text { entire body }\end{array}$ \\
\hline $4 \mathrm{DAH}$ & $4.82 \pm 0.28$ & Fig. 2E & Digestive tract was divided into the anterior and posterior intestine \\
\hline $9 \mathrm{DAH}$ & $5.21 \pm 0.10$ & Fig. $2 \mathrm{~F}$ & Post-larvae stage \\
\hline $14 \mathrm{DAH}$ & $6.43 \pm 0.52$ & Fig. 2G & Teeth developed in both upper and lower jaws \\
\hline $17 \mathrm{DAH}$ & $7.63 \pm 0.71$ & Fig. $2 \mathrm{H}$ & The fin rays of the dorsal and ventral fins had begun to form \\
\hline $25 \mathrm{DAH}$ & $11.32 \pm 1.43$ & Fig. 2I & Juvenile stage \\
\hline $35 \mathrm{DAH}$ & $22.38 \pm 2.58$ & Fig. 2J & $\begin{array}{l}\text { The body's surface was arranged in an alternating pattern of gray-blue } \\
\text { and yellow }\end{array}$ \\
\hline $40 \mathrm{DAH}$ & $30.44 \pm 4.07$ & Fig. 2K & $\begin{array}{l}3 \text { to } 4 \text { vertical green-brown stripes were apparent slightly caudal from } \\
\text { the middle of the body }\end{array}$ \\
\hline $45 \mathrm{DAH}$ & $38.67 \pm 5.65$ & Fig. 2L & The body was silver-gray, and the body shape was similar to adult fish \\
\hline $87 \mathrm{DAH}$ & 236.11 & Fig. $2 \mathrm{M}$ & $\begin{array}{l}\text { The body color was a pale yellow-green, the spots on the side of the } \\
\text { body had disappeared }\end{array}$ \\
\hline
\end{tabular}

at the primordial fin were observed continually from the posterior part of the head, past the tail, to the medial part of the tip of the primordial fin. The body was colorless, and the mouth and anus were not yet open. The primordial fin had formed at the tail (Fig. 2A).

At $1 \mathrm{DAH}$, the larvae exhibited a TL of $4.49 \pm 0.17 \mathrm{~mm}$, while the longest diameter of the yolk and the oil globule diameter had decreased to $0.79 \pm 0.24 \mathrm{~mm}$ and $0.272 \pm$ $0.04 \mathrm{~mm}$, respectively. The mouth had still not opened and melanophores were not yet deposited in the eyes. Xanthophores at the primordial fin reached as far as the tip of the tail. The primordial fin was extended broadly (Fig. 2B). At $2 \mathrm{DAH}$, the larvae were $4.69 \pm 0.16 \mathrm{~mm}$ in $\mathrm{TL}$, and melanophores beginning to be deposited in the eyes and had become black (Fig. 2C). At 3 DAH, the larvae had a $\mathrm{TL}$ of $4.72 \pm 0.07 \mathrm{~mm}$, the yolk was almost completely absorbed and had become decreased in size, while the oil globule was located at the anterior of the yolk. The mouth was open, melanophores were deposited in the eyes, and the larvae had begun feeding on rotifer. Melanophores were present from head to tail, including the chest, back, below the yolk, and below the intestines. The xanthophores of the primordial fin appeared throughout almost the entire body (Fig. 2D). At 4 DAH, the larvae had a TL of $4.82 \pm$ $0.28 \mathrm{~mm}$, and the number of myomeres was $12+14=26$. The yolk had almost completely been absorbed, and 5 bones became visible in the lower jaw. The digestive tract was divided into the anterior and posterior intestine. Melanophores had developed dorsally and ventrally from the head to the tail, while xanthophores were distributed at the end of the mouth, in the body, and in the tail, forming a yellow stripe in the caudal part of the tail. The primordial 

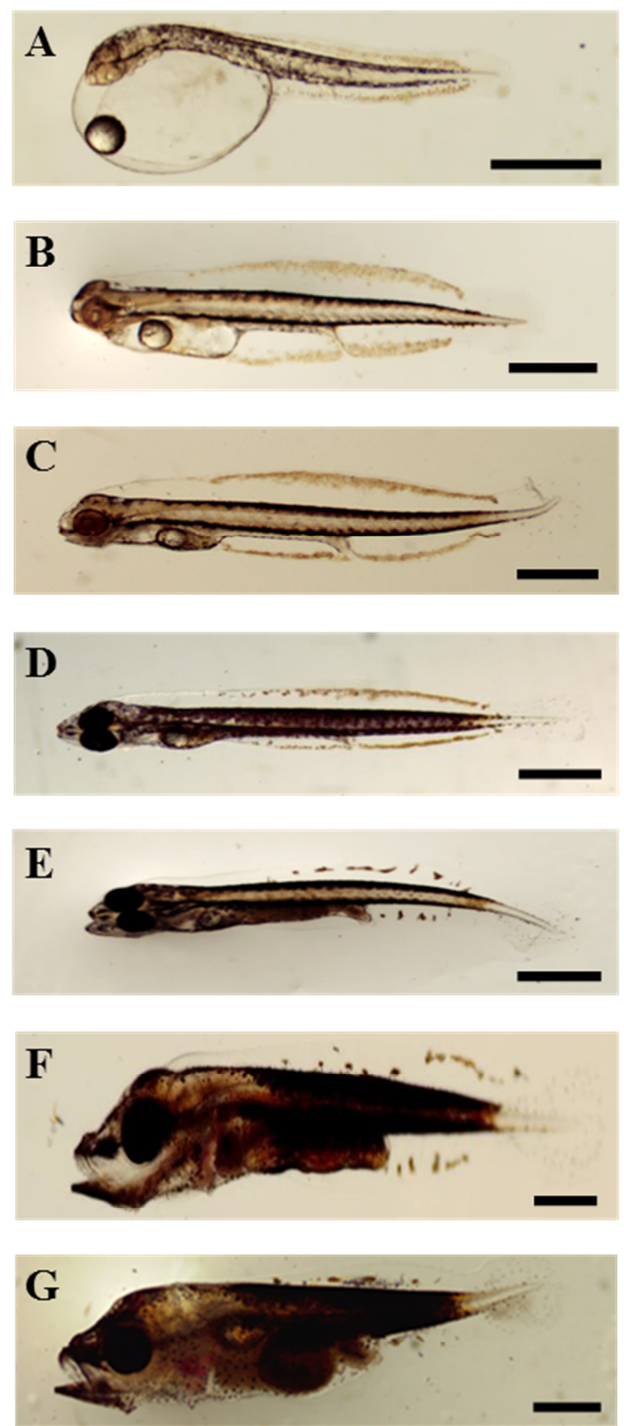
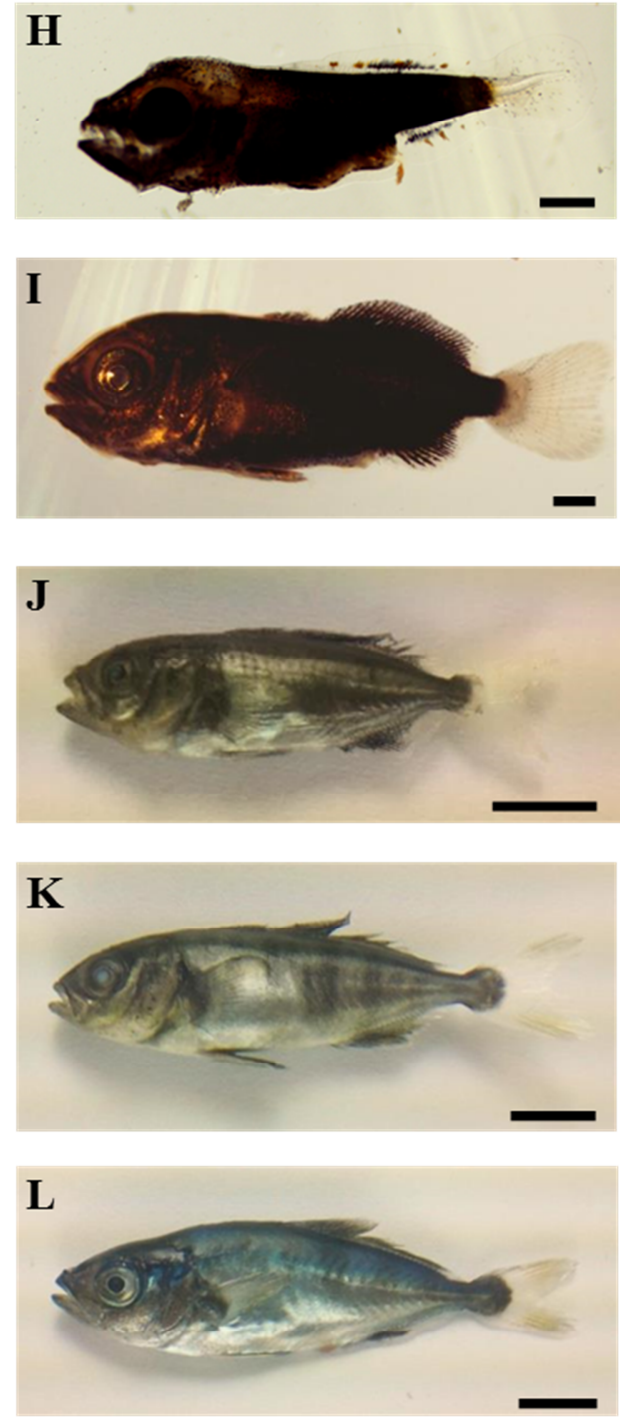

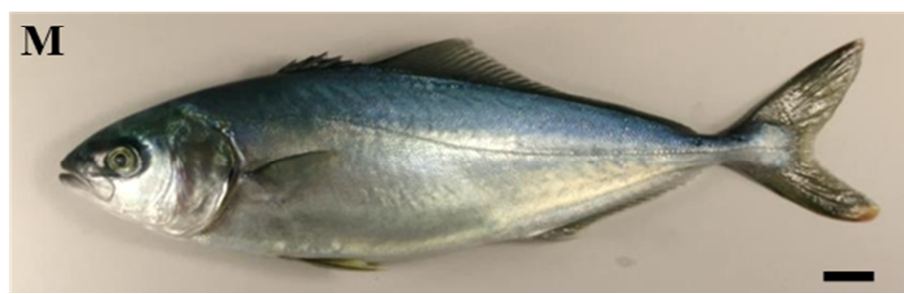

Fig. 2. Morphological development of larva and juveniles of yellowtail kingfish ( $S$. lalandi) at water temperature 20 $\pm \mathbf{0 . 5}{ }^{\circ} \mathbf{C}$. A, Newly hatched larvae, mean $3.62 \pm 0.16 \mathrm{~mm}$ in to total length (TL); B, 1 days after hatching (DAH), mean $4.49 \pm 0.17 \mathrm{~mm}$ in TL; C, $2 \mathrm{DAH}$, mean $4.69 \pm 0.16 \mathrm{~mm}$ in TL; D, 3 DAH, mean $4.72 \pm 0.07 \mathrm{~mm}$ in TL; E, 4 $\mathrm{DAH}$, mean $4.82 \pm 0.28 \mathrm{~mm}$ in TL; F, $9 \mathrm{DAH}$, mean $5.21 \pm 0.10 \mathrm{~mm}$ in TL; G, $14 \mathrm{DAH}$, mean $6.43 \pm 0.52 \mathrm{~mm}$ in TL; H, 17 DAH, mean $7.63 \pm 0.71 \mathrm{~mm}$ in TL; I, $25 \mathrm{DAH}$, mean $11.32 \pm 1.43 \mathrm{~mm}$ in TL; J, $35 \mathrm{DAH}$, mean $22.38 \pm$ $2.58 \mathrm{~mm}$ in TL; K, $40 \mathrm{DAH}$, mean $30.44 \pm 4.07 \mathrm{~mm}$ in TL; L, $45 \mathrm{DAH}$, mean $38.67 \pm 5.65 \mathrm{~mm}$ in TL; M, $87 \mathrm{DAH}$, mean $236.11 \mathrm{~mm}$ in TL. A to I scale bars indicate $1.0 \mathrm{~mm}$, J to $\mathrm{L}$ scale bars indicate $5.0 \mathrm{~mm}$ and $\mathrm{M}$ scale bar indicates $20.0 \mathrm{~mm}$. 
fin xanthophores were gathered partially in the back and abdomen, and had begun to separate (Fig. 2E).

\section{2) Post-larvae stage}

In the post-larvae stage at $9 \mathrm{DAH}$, the TL was $5.21 \mathrm{~mm}$, the body depth had increased, and the upper jaw had formed teeth. The oil globule was almost completely absorbed. The intestine had formed a single coil. Melanophores and xanthophores were distributed throughout the tail and around the intestine. The post-larval fish formed a single distinct yellow band in the caudal part of the tail. In the naked eye examination of the swimming fish, this yellow band appeared as a yellow spot. The body was a faint golden yellow color; the xanthophores of the primordial fin had almost disappeared, and only a few remained towards the ventral and dorsal aspects of the body. A large number of small melanophores remained inside the primordial fin near the tip of the tail, and red spots on the ventral surface of the body spread towards the dorsal surface (Fig. 2F). Individuals at $14 \mathrm{DAH}$ had grown to a TL of $6.43 \pm 0.52 \mathrm{~mm}$, and began to be provided with a mixed feed. At this time, individuals began to show differences in growth. The tip of the tail had begun to lift, and large melanophores with a branched shape were visible in the tail. Teeth developed in both upper and lower jaws. More melanophores appeared in the head, the caudal part of the body in the midline, and around the intestine, while the stem of the caudal fin had grown in size (Fig. 2G). At $17 \mathrm{DAH}$, post-larvae stage fish with a TL of $7.88 \pm 0.70$ $\mathrm{mm}$ had increased in body depth and developed a robust body shape, while the caudal end of the notochord was bent upwards. Inferior to the abdomen, the body depth had begun to increase near the caudal fin, while bones and the caudal fin anlage had appeared below the tail. The primordial fin formed a bulge in the dorsal and ventral aspects of the caudal peduncle, and the fin rays of the dorsal and ventral fins had begun to form. Melanophores and xantho- phores were densely distributed in each area of the body from the head to the tail, and a distinct yellow band was visible on the tail. Observing the fish during swimming, they had plump bodies and a large body depth. The head appeared darkly colored, but the body coloration was faint, and appeared orange with a hint of blue. The yellow band on the tail looked like a yellow spot (Fig. 2H).

\section{3) Juvenile stage}

By $25 \mathrm{DAH}$, the juveniles had grown to a TL of $11.32 \pm$ $1.43 \mathrm{~mm}$. The primordial fin had narrowed, and the dorsal fin had begun to rise, leading to the separation of the first and second dorsal fins. The anal fin had separated from the caudal fin. The juveniles had developed an adult fin morphology, with 6 spines in the first dorsal fin, 1 spine and 34 rays in the second dorsal fin, 1 spine and 15 rays in the pectoral fin, 2 spines in the ventral fin, 1 spine and 21 rays in the anal fin, and 30 rays in the caudal fin. A lateral line had formed from the gill cover to the end of the caudal peduncle (Fig. 2I). By $35 \mathrm{DAH}$, the juveniles had grown to a TL of $15.36 \mathrm{~mm}$. Observing the juveniles swimming the tank, the body was light gray-blue color with yellow stripes on the side of the body and the caudal peduncle immediately posterior to the dorsal fin. The body's surface was arranged in an alternating pattern of gray-blue and yellow. When the juveniles received an external shock, they momentarily displayed a light orange color over the whole body, with vivid spots on the side of their body (Fig. 2J). By 40 DAH, the juveniles had grown to a TL of $30.44 \pm 4.07 \mathrm{~mm}$. The body depth grew larger, while the color of the body was black, yellow, and light gray-blue, while 3-4 vertical green-brown stripes were apparent slightly caudal from the middle of the body. The first dorsal fin, second dorsal fin, and anal fin were blue-green with a slight yellow tint, while the pectoral fin and caudal fin were transparent and colorless (Fig. 2K). At 45 DAH, the juveniles were 38.67 $\pm 5.65 \mathrm{~mm}$ in TL and $10.10 \pm 0.94 \mathrm{~mm}$ in body depth. 
They were a green color with a faint orange tint, with 7 green-brown stripes on the sides of their bodies. The first dorsal fin, second dorsal fin, and anal fin were a faint yellow in color, and melanophores were well developed around the base of each fin. The ventral fin was large, with a deep yellow color and well developed melanophores in the middle part. The pectoral fin was colorless, the caudal fin was a faint yellow color, and the number of branches in the caudal fin had increased to 8. Below the abdomen, the body was silver-gray, and the body shape was similar to adult fish (Fig. 2L). At $87 \mathrm{DAH}$, the juveniles had grown to $236.11 \mathrm{~mm}$ in TL, $217.68 \mathrm{~mm}$ in fork length, and 136.5 $\mathrm{g}$ in weight. The body color was a pale yellow-green, the spots on the side of the body had disappeared, and the tip of the caudal fin was yellow (Fig. 2M).

\section{Larval behavior and rearing management}

Newly hatched larvae floated with their heads above the water for several hours after hatching, but after several hours, the larvae flipped so that their heads were at the bottom and their tails were in the air. On occasions, they positioned their body horizontally or made sudden swimming movements. At 48 hours after hatching, the larvae opened their mouths. Although they did not feed on rotifer, even if it was provided at this time, at 72 hours after hatching they achieved a TL of $5.1 \mathrm{~mm}$. Their melanophores were deposited in their eyes, and they began to feed on rotifer at this stage. At $9 \mathrm{DAH}$, the oil globule had been almost entirely absorbed. Entering the post-larvae stage, body depth increased, and they began to eat Artemia in addition to rotifer as the teeth in their upper jaws developed. At 14 $\mathrm{DAH}$, they had grown to a TL of $6.18 \pm 0.15 \mathrm{~mm}$, had formed teeth in both the upper and lower jaw, and were provided with mixed feed. At this time, individuals began to exhibit large changes in TL, depending on their feeding ability. From $30 \mathrm{DAH}$, they were fed striped beakfish eggs or hatchlings. In this study, the rate of growth was reduced between 15 and $30 \mathrm{DAH}$, but growth improved as the fish began feeding on striped beakfish eggs and hatchlings. The yellowtail kingfish (S. lalandi) at $35 \mathrm{DAH}$ exhibited a light gray-blue coloration to their body, yellow stripes on their sides and on the caudal peduncle immediately posterior to the dorsal fin. They had a distinct lateral line at this point. They were sensitive to external shocks, momentarily displaying vivid spots on the side of their body and a pale orange color over their whole body during those. At 45 $\mathrm{DAH}$, the juveniles were a green color with a hint of pale orange. When they received an external shock, the juveniles displayed 7 pale green-brown stripes on the sides of their body. This is consistent with reports on the morphological development of yellowtail kingfish $(S$. lalandi) by Fujita and Yogata (1984).

During the juvenile stage, yellowtails and greater amberjacks swim in schools around floating seaweed. Conversely, because yellowtail kingfish ( $S$. lalandi) do not exhibit this behavior, the juveniles are difficult to capture in the wild (Fukuhara et al., 1986; Sakakura \& Tsukamoto, 1996). In the present study, juveniles at $40 \mathrm{DAH}$ with a TL of 23 $\mathrm{mm}$ tended to hide underneath a PVC tube that had been suspended at an intermediate depth within the tank. Cannibalism has been reported in the course of seed production for yellowtail (Mizuta, 1981; Sakakura \& Tsukamoto, 1996), greater amberjack (Shiozawa et al., 2003) and yellowtail kingfish (S. lalandi) (Ebisu \& Tachihara, 1993). No cannibalistic behavior was observed in this study. Nevertheless, a high rate of individuals exhibited impaired embryotic, larval, or juvenile development. Future studies are therefore required to improve management of the rearing environment so as to reduce the rate of impaired development.

\section{ACKNOWLEDGMENTS}

This study was conducted as part of the National Institute of Fisheries Science' Fisheries Research Project to develop 
technologies for the commercialization of yellowtail farming (R2016008).

\section{REFERENCES}

Byun SG (2002) Reproductive biological characteristics and early development of slime flounder, Microstomus achne. Doctorial thesis, Yeosu University, Yeosu, South Korea, 162 pp.

Chen B, Qin J, Kumar M, Hutchinson W, Clarke S (2006a) Ontogenetic development of the digestive system in yellowtail kingfish Seriola lalandi larvae. Aquaculture 256:489-501.

Chen B, Qin J, Kumar M, Hutchinson W, Clarke S (2006b) Ontogenetic development of digestive enzymes in yellowtail kingfish Seriola lalandi larvae. Aquaculture 260: 264-271.

Ebisu R, Tachihara K (1993) Mortality caused by cannibalism in seed production of gold striped amberjack Seriola lalandi. Bulletin Nagasaki Prefecture Institute Fisheries 19:1-7 (in Japanese).

Fujita S, Yogata T (1984) Induction of ovarian maturation, embryonic development and larvae and juveniles of the amberjack, Seriola aureovittata. Jap J Ichthyol 30:426434.

Fukuhara O, Nakagawa T, Fukunaga T (1986) Larval and juvenile development of yellowtail reared in the laboratory. Nippon Suisan Gakkaishi 52:2091-2098.

Kim IS, Choi Y, Kim BJ (2001) Percoidei fishes of Korea. Korea Research Institute of Bioscience and Biotechnology Korea. pp. 279.

Mizuta Y (1981) On the seedling production of Buri, Seriola quinqueradiata. Saibai Gyogyo Gijyutsu Kaihatsu Kenkyu (Technical Reports of Japanese Sea Ranching Programs) 10:85-97 (in Japanese).

Moran D, Gara B, Wells RMG (2007a) Energetics and metabolism of yellowtail kingfish (Seriola lalandi
Valenciennes 1833) during embryogenesis. Aquaculture 265:359-369.

Moran D, Smith CK, Gara B, Poortenaar CW (2007b) Reproductive behaviour and early development in yellowtail kingfish (Seriola lalandi Valenciennes 1833). Aquaculture 262:95-104.

Nakabo T (1993) Fishes of Japan with Pictorial Keys to the Species. Tokai University Press. Tokyo. pp. 1474. (in Japanese)

Nakada M (2000) Yellowtail and related species culture. In: Stickney RR (ed.), Encyclopedia of Aquaculture. John Wiley \& Sons, Inc., New York, pp 1007-1036.

Nakada M (2002) Yellowtail culture development and solutions for the future. Rev Fish Sci 10:559-575.

Nakada M (2008) Capture-based aquaculture of yellowtail. In Lavatelli A, Holthus PF (eds.), Capture-based AquaCulture. Global overview. FAO Fisheries Technical Papter. FAO., Rome, pp 199-215.

Poortenaar CW, Hooker, SH, Sharp N (2001) Assessment of yellowtail kingfish (Seriola lalandi lalandi) reproductive physiology, as a basis for aquaculture development. Aquaculture 201:271-286.

Sakakura Y, Tsukamoto K (1999) Ontogeny of aggressive behaviour in schools of yellowtail Seriola quinqueradiata. Environ Biol Fishes 56:231-242.

Shiozawa S, Takeuchi, H, Hirokawa J (2003) Improved seed production techniques for the amberjack, Seriola dumerili. Saibai Giken 31:11-18. (in Japanese).

Song YB, Lee CH, Kang HC, Kim HB, Lee YD (2013) Effect of water temperature and salinity on the fertilized egg development and larval development of sevenband grouper, Epinephelus septemfasciatus. Dev Reprod 17: 369-377.

Stuart K, Drawbridge M (2012) Spawning and larval rearing of California Yellowtail (Seriola lalandi) in Southern California. Bull Fish Res Agen 35:15-21. 